\title{
Masonry block construction in Haiti
}

\author{
L. Holliday ${ }^{1}$, C. Ramseyer ${ }^{2} \&$ F. H. Grant ${ }^{3}$ \\ ${ }^{1}$ Division of Construction Science, University of Oklahoma, \\ Norman Oklahoma, USA \\ ${ }^{2}$ Department of Civil Engineering, University of Oklahoma, \\ Norman, Oklahoma, USA \\ ${ }^{3}$ Department of Industrial Engineering, University of Oklahoma, \\ Norman, Oklahoma, USA
}

\begin{abstract}
Most of the building failures in Haiti during the January 12th, 2010 earthquake were CMU block buildings. It is the locally preferred building material. Since it is difficult to import materials into Haiti, CMU block is made with local sand (sometimes beach sand which includes a significant amount of salt) and aggregate and only requires Portland cement to be imported. The blocks are made in a press-type machine without steam and at comparatively little pressure. The blocks contain as little as 1/30th Portland cement by volume and are left in a yard to dry cure, rather than moist curing. The blocks are sometimes so weak that they must be handled by workers with two hands or they break under their own weight. Tests at the University of Oklahoma reveal the blocks have an extremely low compressive strength (as low as 300 psi). Given the typical construction techniques used in Haiti, which include heavy concrete slab roof, focusing on hurricane resistance rather than earthquakes, the current CMU block fabrication method was a recipe for disaster that was realized.

OU researchers worked with local Haitian organizations, primarily at Christianville Mission, to improve the quality of CMU blocks in Haiti. They provided guidelines for the CMU block mix, and curing instructions. Tests show the compressive strength of the CMU block has increased by more than three times with relatively little additional cost. This paper discusses the problems with current fabrication techniques for CMU block in Haiti, changes which can be made with relatively little cost or effort, and the resulting improvements in block strength realized.
\end{abstract}

Keywords: masonry, Haiti, earthquake. 


\section{Introduction and history of Christianville}

Christianville has a long and rich history in its mission work for children. It began in the 1960s as an orphanage. Legend has it that "Papa Doc", the infamous dictator of Haiti, originally donated the land for the orphanage and hired a woman from Jamaica to run it. It operated in this mode for several years. One of the sons of that woman, Wayne Herget, is still involved with Christianville. He currently lives in Atlanta, but has spent as much as 15 years living in Haiti and knows the country and local community well.

This mission was expanded to agriculture education, which eventually replaced the orphanage function. It began as an education source for raising pigs, and expanded to raising freshwater fish, primarily Tilapia. This still exists today except that the pig production was replaced by goat production as it is a more efficient conversion of feed to protein. Egg farming was also added about 10 years ago and the mission now produces 800 eggs per day, used primarily for food for the students attending the mission education program. There is also a building owned by the Haitian Fisheries Ministry on the grounds of Christianville. This is an education resource for visiting students and scholars concerned with fish production. It is a recently constructed building but was heavily damage during the earthquake.

A church in Indiana, First Christian, eventually adopted the education component of Christianville and, over many years, built several buildings to support education. These buildings included a preschool, elementary school, high school, and college. Most of these original buildings were destroyed or heavily damaged in the earthquake of 2010. The mission is now working on rebuilding some of those buildings and redefining the scope of its education mission.

Christianville also houses other missions in the form of a medical clinic, and eye clinic, and a dental clinic. These are sponsored by various or individuals agencies in the US. They have little connection to the Christianville education mission other than proximity.

Christianville also hosts mission teams and has a facility to house and feed these teams. Most of them are now focused on repairing or rebuilding damaged buildings. They have two dormitory facilities also with private rooms for some of the longer term volunteers.

\section{Building practices and materials}

In recent times there has been a shortage of wood in Haiti and this has led to a trend in which building construction there relies heavily on Portland cement. Buildings are sometimes constructed of reinforced concrete but this requires wooden formwork, in a land where 1"x4" wooden formwork pieces are so valuable, they are recycled till they will no longer function. Building with CMU block requires less formwork and therefore it has become the more popular choice for construction. Most buildings seen from the street in Port of Prince are constructed of CMU block walls (or sometimes reinforced concrete walls) with 


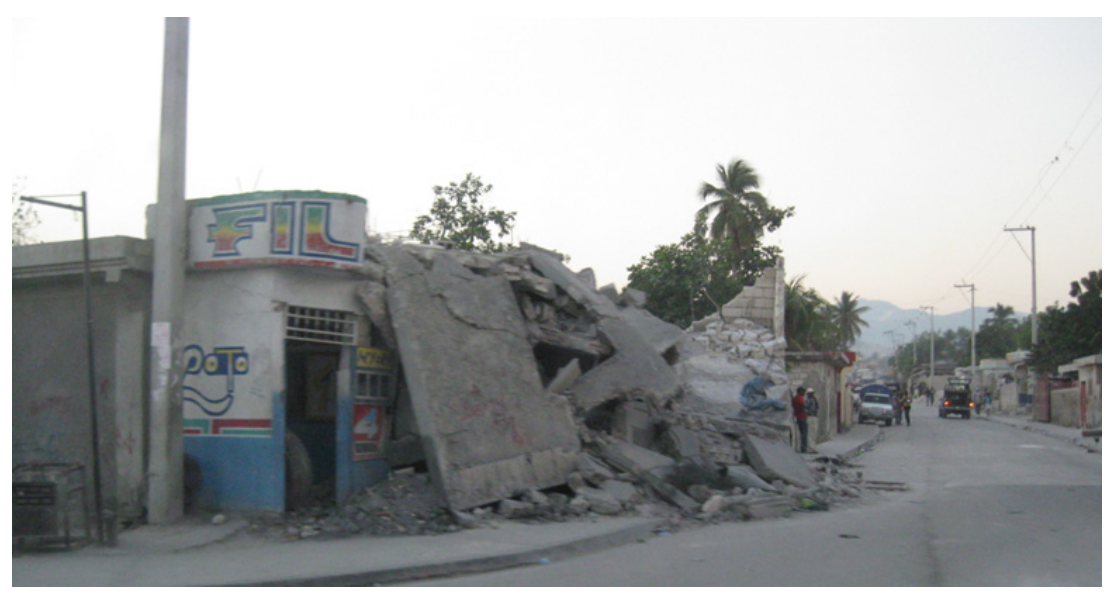

Figure 1: Typical buildings in Port-au-Prince, Haiti shown following the earthquake.

reinforced concrete slab roofs and floors (Figure 1). After the earthquake it is obvious upon inspection that these buildings were constructed with little steel reinforcement and poor connection details.

\section{Lack of building materials and building standards}

There are many factors that contribute to the poor quality of construction in Haiti. There are no building or material standards in place to control the quality of construction. In addition to this, years of poverty have slowly reduced the quality of materials made in-country. For example, during building inspections at Christianville, it was noted that older buildings were built with better quality concrete and masonry block. Over the years, in an attempt to save money, the amount of Portland cement used was reduced. In the most recently built buildings, the CMU block was of such poor quality that workers had to handle the blocks with two hands. Otherwise the blocks would break apart under their own weight. In addition to the poor materials used in construction, the methods of construction also reduce building quality. Residents build their own homes and are therefore left to determine the important structural details themselves. In addition to this homes are built slowly as resources are available. If a homeowner is able to save a few funds they put this into building materials as a way to slowly save for a home. This pace makes it difficult to hire craftsmen who would be trained to construct with recommended standards.

\section{Performance of CMU block buildings}

There were several buildings at Christianville built of CMU block. Of the CMU block buildings there were two different structural systems at Christianville: 1) 
buildings built entirely of CMU block and 2) building built of a hybrid of reinforced concrete beams and columns with CMU block walls.

Most of the buildings constructed using CMU were a hybrid of reinforced concrete frames and CMU walls. The reinforced concrete frames are built with little attention to detailing at beam-column connections which results in low moment capacity of the frames [1]. Because of these low moment capacity frame connections, the building relies heavily on the CMU walls to resist lateral loads [2]. Additionally, as seen in Figure 2, it is very common for the second story to cantilever over the first story. This creates a structural irregularity in the perimeter wall system where a great deal of the lateral load resisting system is located.

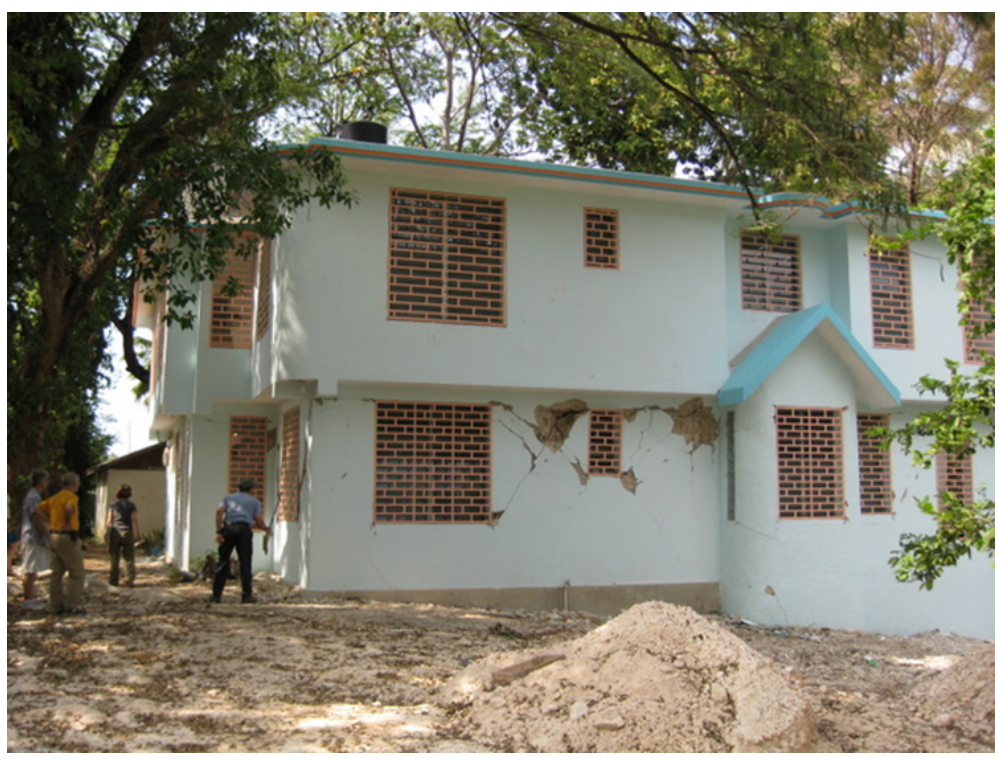

Figure 2: Newly constructed building which is a hybrid of reinforced concrete and CMU block.

There were seven hybrid buildings at Christainville and of these seven buildings, four were two-story buildings which all collapsed or were damaged beyond repair. The three one- story hybrid system buildings performed better. Only one collapsed, one was severely damaged, and one remained undamaged. It is worth noting that the undamaged building had a lightweight steel roof. Several of these hybrid buildings that failed were newly constructed buildings where the CMU block performed poorly as a shear wall (figures 4-6).

There were four buildings constructed of CMU blocks (without reinforced concrete beams and columns) with light-weight steel roofs that consisted of steel trusses or bar joists with metal panels. All four of these building performed well and showed almost no signs of damage. 

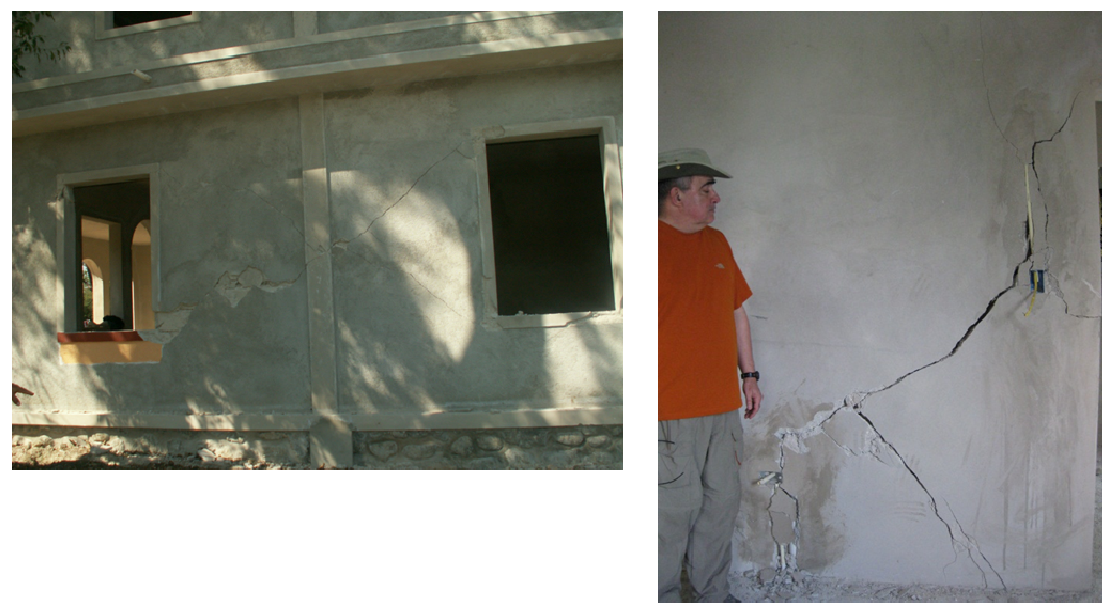

Figure 3: Wall shear failure in newly constructed hybrid reinforced concrete and CMU block (left outside view, right inside view).

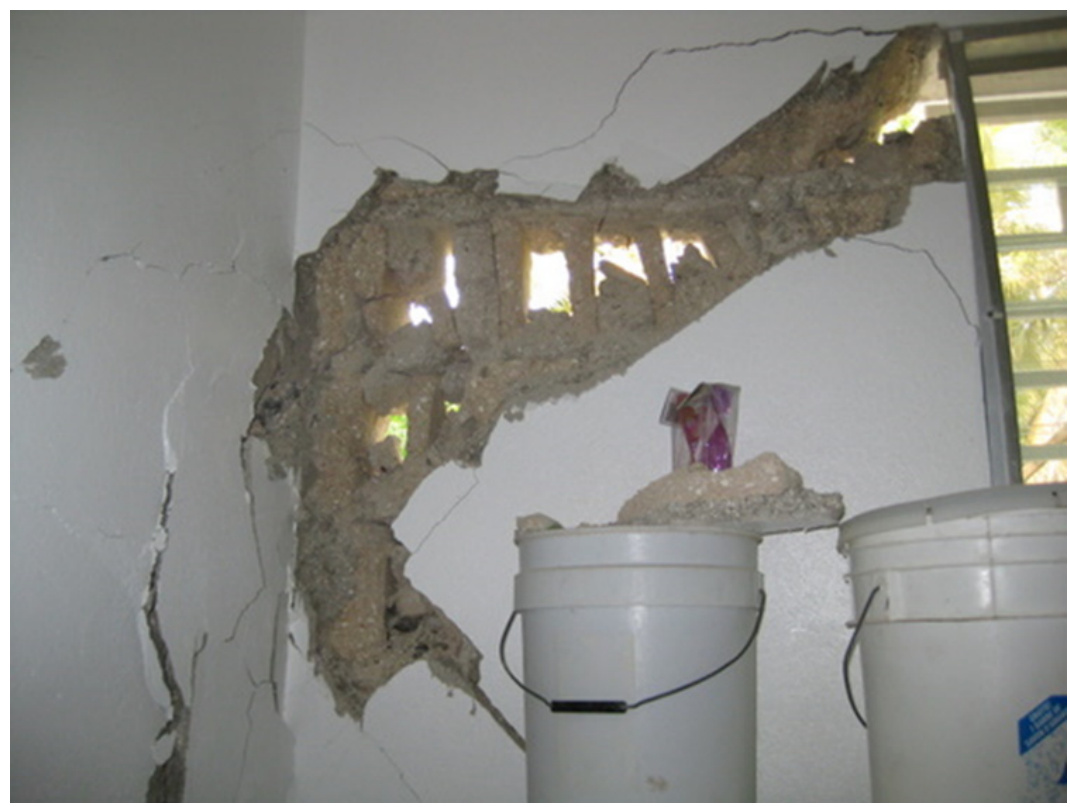

Figure 4: Newly constructed building with a hybrid system of reinforced concrete with CMU block.

\section{Block making in Haiti}

CMU blocks used in building construction in Haiti are made locally. They are often made with hand operated mechanical presses as shown in Figure 5. They 


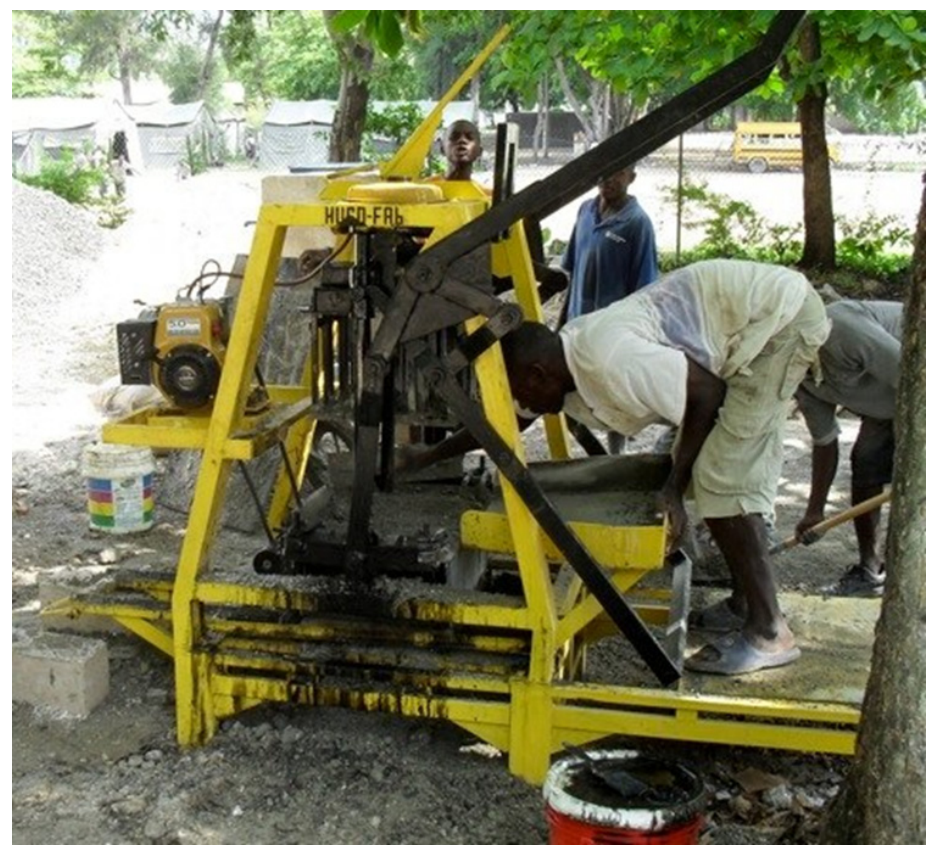

Figure 5: $\quad$ Machine used to make CMU block in Haiti.

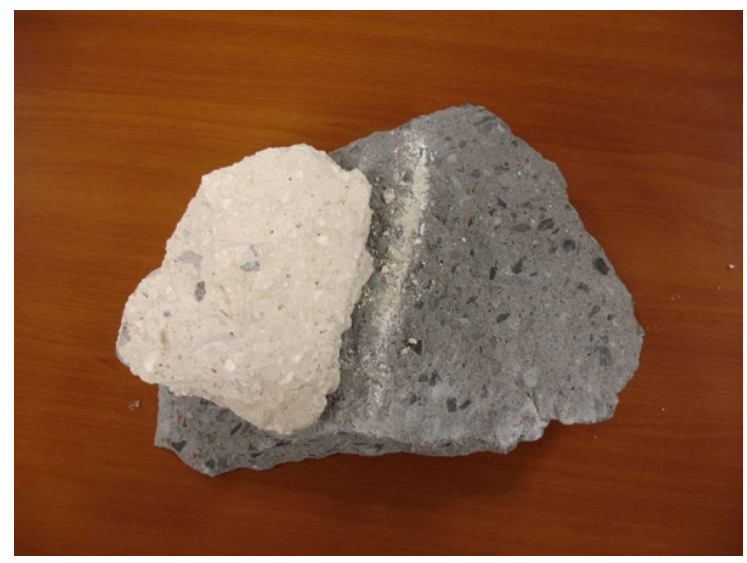

Figure 6: Sample of Haitian concrete (left) and a typical US concrete sample (right). Note the Haitian concrete is loose and chalky and able to leave a chalk line with very little pressure.

are made with local sand and gravel. These ingredients are often of poor quality. The sand may contain salt and the gravel is typically smooth shaped rather than jagged in shape so the bond to the cement paste is not as strong as it could be. The Portland cement, which is the only imported ingredient, is often of poor quality and visual inspection indicated (by a gritty texture of the powder) that it 
was partially hydrated. Workers interviewed said the mix for the block consisted of mostly sand and gravel with as little as 1/30th Portland cement. Rather than having a characteristic gray color found in a properly produced CMU, these blocks have so little Portland cement they are white or yellow in color. The newly constructed blocks are placed (uncovered) in the sun to dry and with no attention to typical curing processes such as controlled humidity. Blocks are not steamed during curing and often formed under little or no pressure. Figure 6 shows a sample of Haitian concrete next to a typical US sample of concrete. Blocks are sometimes so weak that workers must lift blocks with two hands or else blocks fall apart. Visual inspections indicate the block is of poor quality and testing verified this.

\section{Testing of CMU block}

Samples from several CMU block buildings were tested at the Donald G. Fears Structural Engineering Laboratory at the University of Oklahoma [3-7]. The first set of samples was taken from the buildings damaged during the earthquake. The results from the compression tests of these samples are shown in Table 1. In the case of the building shown in Figures 2 and 3, the mortar coating the blocks had a higher compressive strength than the blocks themselves.

Table 1: $\quad$ Compressive test results for Haitian CMU samples.

\begin{tabular}{|c|c|}
\hline Sample description & $\begin{array}{c}\text { Compressive strength } \\
\text { (psi) }\end{array}$ \\
\hline Block samples from the building shown in Figure 4 & 745 \\
\hline Sample 1 & 545 \\
\hline Sample 2 & 1135 \\
\hline Sample 3 & 890 \\
\hline Block samples from the building shown in Figures 2 and 3 & 555 \\
\hline Sample 1 & \\
\hline Sample 2 & 655 \\
\hline Samples from an older building (hybrid structural system) & 1908 \\
\hline Sample 1 & 470 \\
\hline Sample 2 (interior mortar coating) & 493 \\
\hline Samples of Haitian locally purchased CMU block & 1538 \\
\hline Sample 1 (made of local Marl aggregate) & 1282 \\
\hline Sample 2 (made of river rock aggregate) & \\
\hline Sample 3 & \\
\hline Sample 4 & \\
\hline
\end{tabular}

After confirming the poor strength of the blocks purchased in Haiti, Christianville officials decided to begin making their own block to have greater control over the quality of block used to rebuild. Christianville purchased a block maker (figure 5) and researchers at OU advised the officials on CMU block making. The amount of Portland cement was increased to $1 / 6$ th by volume. The sand and/or small aggregate used in the mix was not smooth river 
sand and the blocks were moistened during curing. Christianville officials found it difficult to keep the block moist during the entire 28 days of curing, but did moisten the blocks several times a day. Samples of the improved blocks were tested and the results are shown in Table 2. Visual inspection of the samples indicated there is still a portion of the Portland cement that is not activated and therefore there is still room for improvement in the curing process, but overall the compressive strength was improved.

Table 2: $\quad$ CMU block sample compressive strength after improved mix and curing.

\begin{tabular}{|c|c|}
\hline Sample description & Compressive strength (psi) \\
\hline Sample 1 & 1198 \\
\hline Sample 2 & 1937 \\
\hline
\end{tabular}

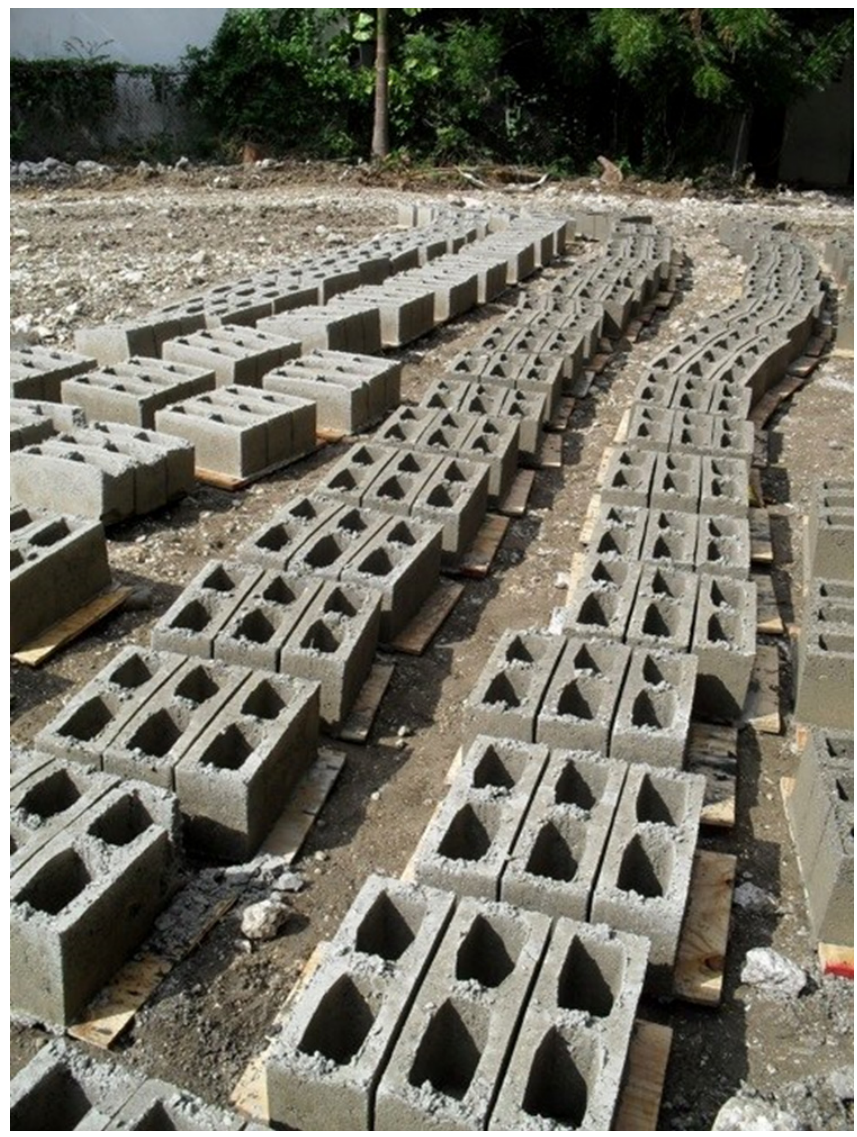

Figure 7: Newly constructed CMU blocks made in Haiti with an improved mix and curing techniques. Note: The improved CMU blocks are now grey in color. 


\section{Conclusions}

Over years of harsh economic conditions in Haiti the quality of building materials steadily declined until the Earthquake of 2010 clearly illustrated these deficiencies. Changing a few key practices in the block making process increased the compressive strength by roughly $200 \%$. The number of samples for testing is small and testing should continue as the production of block continues. In the future, a hand testing machine for easily checking the compressive strength of a block in the field would help control the quality of CMU blocks made in developing areas where commercial testing is not available. The authors are working on the design of a block testing system that can be built in the field. It is based on a lever system with known force (weight) application, without hydraulic measurement. It will be a low cost application that will measure threshold strength of the block for a pass/no pass evaluation.

\section{References}

[1] ACI Committee 318,Building Code Requirements for Structural Concrete (ACI 318-08) and Commentary (ACI 318R-08), American Concrete Institute, Farmington Hills, MI, 2008

[2] Masonry Standards Joint Committee (MSJC), Specification and Commentary for Masonry Structures(ACI 530.1-05/ASCE 6-05/TMS 60205), Farmington Hills, MI, 2006

[3] ASTM Standard C90, Standard Specification for Loadbearing Concrete Masonry Units (C90-11) ASTM International, West Conshohocken, PA, 2011

[4] ASTM Standard C1714, Standard Specification for Preblended Dry Mortar Mix for Unit Masonry (C1714/C1714M-10), ASTM International, West Conshohocken, PA, 2010

[5] ASTM Standard C140, Standard Test Methods for Sampling and Testing Concrete Masonry Units and Related Units (C140-11) ASTM International, West Conshohocken, PA, 2011

[6] ASTM Standard C270, Standard Specification for Mortar for Unit Masonry (C270-10), ASTM International, West Conshohocken, PA, 2010

[7] ASTM Standard C144, Standard Specification for Aggregate for Masonry Mortar (C144-04) ASTM International, West Conshohocken, PA, 2004 